OPEN ACCESS

Edited by:

Allison A. Appleton,

University at Albany, United States

Reviewed by:

Roch A. Nianogo,

UCLA School of Public Health,

United States

Elizabeth Holdsworth,

Washington State University,

United States

*Correspondence:

Francisco Alejandro Montiel Ishino francisco.montielishino@nih.gov orcid.org/0000-0002-2837-726X

${ }^{\dagger}$ Present address:

Francisco Alejandro Montiel Ishino,

Division of Intramural Research, National Institute on Minority Health

and Health Disparities, National Institutes of Health, Bethesda, MD,

United States

Specialty section:

This article was submitted to Life-Course Epidemiology and Social Inequalities in Health, a section of the journal

Frontiers in Public Health

Received: 10 December 2020 Accepted: 29 November 2021

Published: 20 December 2021

Citation:

Montiel Ishino FA, McNab $P$. Villalobos $K$, Cohen JH, Nápoles AM and Williams F (2021) Hispanic/Latino Acculturation Profiles and Telomere Length: Latent Class Analysis on a Nationally Representative Sample.

Front. Public Health 9:640226.

doi: 10.3389/fpubh.2021.640226

\section{Hispanic/Latino Acculturation Profiles and Telomere Length: Latent Class Analysis on a Nationally Representative Sample}

\author{
Francisco Alejandro Montiel Ishino ${ }^{1 *}$, Philip $\mathrm{McNab}^{2}$, Kevin Villalobos ${ }^{1}$, \\ Jeffrey H. Cohen ${ }^{3}$, Anna M. Nápoles ${ }^{1}$ and Faustine Williams ${ }^{1}$ \\ ${ }^{1}$ Division of Intramural Research, National Institute on Minority Health and Health Disparities, National Institutes of Health, \\ Bethesda, MD, United States, ${ }^{2}$ Department of Environmental Health \& Engineering, Center for a Livable Future, Johns \\ Hopkins Bloomberg School of Public Health, Baltimore, MD, United States, ${ }^{3}$ Department of Anthropology, The Ohio State \\ University, Columbus, $\mathrm{OH}$, United States
}

Background: Acculturation profiles and their impact on telomere length among foreign-born Hispanics/Latinos living in the United States (US) are relatively unknown. The limited research available has linked acculturation with shortened telomere length.

Objectives: To identify acculturation profiles among a US representative sample of Hispanics/Latinos and to then examine telomere length differences between profiles.

Methods: We conducted a latent class analysis among a non-institutionalized US-representative sample of Hispanics/Latinos using the 1999-2002 National Health and Nutrition Examination Survey $(N=2,292)$. The latent variable of acculturation was assessed by length of time in the US and language used as a child, read and spoken, usually spoken at home, used to think, and used with friends (i.e., Spanish and/or English). Telomere length assessed from leukocytes was used as the distal continuous outcome.

Results: We identified five profiles: (1) low acculturated [33.2\% of sample]; (2) partially integrated [18.6\% of sample]; (3) integrated [19.4\% of sample]; (4) partially assimilated [15.1\% of sample]; and (5) assimilated [13.7\% of sample]. Acculturation profiles revealed nuanced differences in conditional probabilities with language use despite the length of time spent in the US. While telomere length did vary, there were no significant differences between profiles.

Conclusion: Profiles identified revealed that possible life-course and generational effects may be at play in the partially assimilated and assimilated profiles. Our findings expand public health research using complex survey data to identify and assess the dynamic relationship of acculturation profiles and health biomarkers, while being among the first to examine this context using a person-centered approach.

Keywords: acculturation, telomere length (TL), latent class analysis (LCAs), Hispanic (demographic), complex survey data, Latino (Hispanic) 


\section{INTRODUCTION}

Acculturation is a dynamic process by which individuals, often immigrants, enter into a new host culture $(1,2)$ that has both indirect and direct effects on behavior and biology $(3,4)$. A particular biological marker or biomarker of interest are telomeres-caps of tandem repeat nucleotide sequences at the end of chromosomes that help protect cellular information during replication. The caps diminish as cells divide. As such, telomere length has been used as a biomarker of cellular aging or senescence (5-7). This diminishment has been used to predict accelerated senescence and senescence-associated diseases that increase morbidity and mortality in specific population profiles (8-13), and may be affected by the acculturative process (14).

Senescence-associated diseases include cardiometabolic disorders (e.g., type II diabetes), neurodegeneration (e.g., Alzheimer's and Parkinson's disease), and some types of cancers (15-17). Moreover, the common factors associated with telomere shortening in both animal and human studies are lifestyle and stress. Lifestyle and demographic factors including physical activity, diet, and nicotine use, as well as socioeconomic status have been linked to telomere length $(7,11,18)$. A possible mechanistic pathway is that stress causes an oxidative response that affects humans at a cellular level, whereby cells dividing more frequently shorten telomeres and cause apoptosis at higher rates $(6,15)$. The stressful process of acculturation has been found to have a shortening effect on telomere length (14), and therefore acculturation may be associated with shortened telomeres. Other environmental factors and exposures that have been associated with telomere length may be directly and indirectly related to acculturation; these include biological ancestry categorized by race/ethnicity, poverty, and the built environment of-and environmental exposures from-neighborhoods $(19,20)$.

Acculturation has been associated with negative health consequences among Hispanics/Latinos (21-24) and other underrepresented groups such as African Americans (25-27). Acculturation may then further exacerbate health disparities in already-vulnerable groups. Among Hispanics/Latinos acculturation has been historically measured by language use. One longstanding validated linguistic acculturation measure is the Short Acculturation Scale for Hispanics (SASH), originally developed by Marin and colleagues (28) and recently validated by Hamilton and colleagues (29). While linguistic acculturation is used as a powerful measure to ascertain an individual's strategy to separate, integrate, marginalize, or assimilate into a new culture in the United States (US) $(2,30)$, it is unknown how the process is directly related to health biomarkers like telomere length.

Our study builds upon the limited research on acculturation and telomere length, especially among US Hispanics/Latinos. We used latent class analysis (LCA) to, first, identify acculturation profiles among US Hispanics/Latinos based on a nationally representative sample. Our second objective was to examine if differences in telomere length among identified Hispanic/Latino acculturation profiles existed. We proposed that at least three heterogenous profiles of acculturation would be identified. We hypothesized that telomere length would be significantly different between the identified acculturation profiles. We based our hypothesis on a study by Ruiz and colleagues (14) focused on a cohort of Mexican-American pregnant mothers' telomere length as it related to acculturation, discrimination, depression, and their levels of psychosocial stress. Ruiz and colleagues (14) reported a strong relationship between shortened telomere length and mothers' latent variables of negative affect from stressful experiences and acculturation strategies oriented toward US host culture, especially when compared to newly immigrated mothers.

\section{MATERIALS AND METHODS}

LCA refers to a person-centered technique used to identify unobservable, or latent, profiles within a population $(31,32)$. We conducted LCA using the National Health and Nutrition Examination Survey (NHANES) US Hispanic/Latino adult (18 years old and older) sample from the 1999-2002 cycles. Hispanic/Latino was operationalized based on NHANES defined race/ethnicity variables that self-identified as Mexican American and Hispanic. The 1999-2002 NHANES cycles allowed us to assess the impact of multiple acculturation factors on mean leukocyte telomere length. The 1999-2002 sample includes useable data from 2,292 Hispanic/Latino participants with acculturation questionnaire data and telomere length data. The Institutional Review Board assessed the research protocol, and as no human participants were involved in this study no approval was necessary. The secondary data analyzed from the 1999-2002 NHANES cycle are publicly available from the Centers for Disease Control and Prevention-National Center for Health Statistics database (https://wwwn.cdc.gov/nchs/nhanes/Default. aspx). A detailed description of the sampling methods and study procedures is available elsewhere (33). Sampling weights were included in all analyses to adjust for survey non-response and sample selection probabilities for the 1999-2002 cycles. Primary sampling units and stratum variables were included to account for the NHANES complex sampling design. All data and analytical files are available upon reasonable request.

\section{Measures}

\section{Acculturation}

We developed our acculturation latent variable from length of time in the US and language used among Hispanics/Latinos, i.e., Mexican American and other Hispanics. Other Hispanics, as reported in the NHANES, were participants that identified as Hispanic not of Mexican descent. Length of time was split into four categories: (1) $<1$ year; (2) $1-<5$ years; (3) $5-<10$ years; and (4) 10 years or more (34-36). Language specific questions were modeled after the SASH, which was originally developed by Marin and colleagues (28). The NHANES acculturation questionnaire gauged language used in the context of: (1) as a child; (2) for reading and speaking; (3) at home; (4) to think; and (5) with friends. Response options for all language used questions were: (1) only Spanish; (2) more Spanish than English; (3) both equally; (4) more English than Spanish; and (5) only English.

\section{Telomere Length}

NHANES collected blood from participants to conduct biomarker and other biological analyses. Telomere data were 


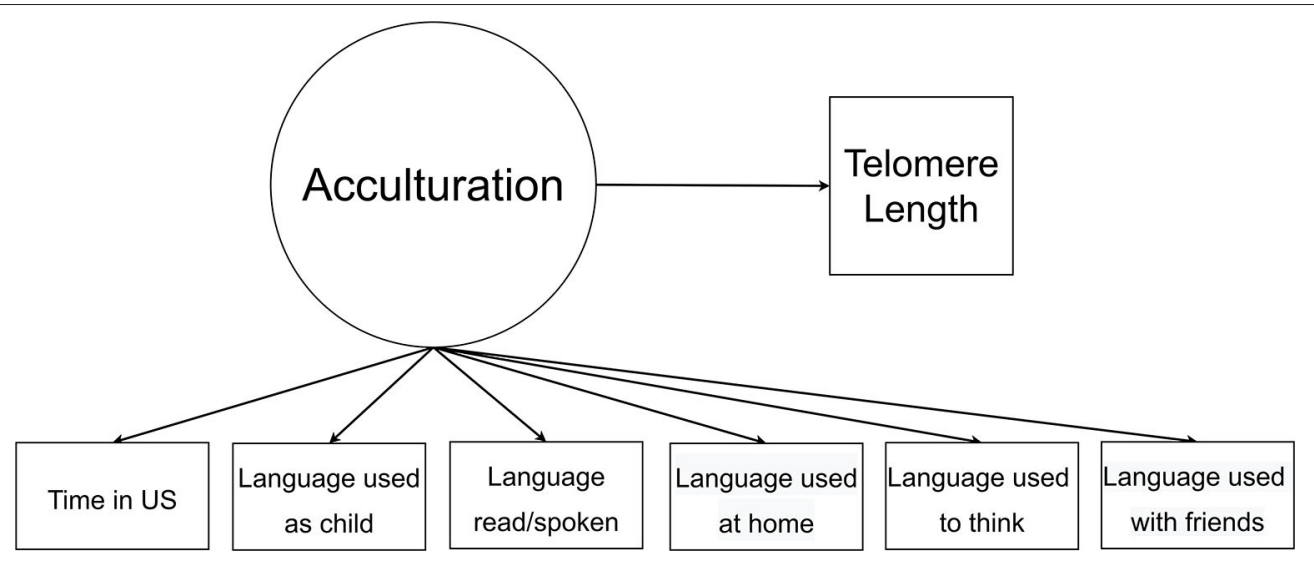

FIGURE 1 | Latent class analysis model of acculturation where the circle represents latent variable and rectangles represent observed indicator variables.

only publicly available during the 1999-2002 NHANES cycles. Telomere length was assessed from leukocyte assays performed using a quantitative polymerase chain reaction method to measure length relative to standard reference DNA or T/S ratio. See Needham and colleagues (11) for greater detail on lab assay techniques.

\section{Sociodemographic and Lifestyle Descriptive Variables}

Variables such as gender/sex (i.e., male and female), US citizenship (i.e., no or yes), less than a high school education (i.e., no or yes), smoked at least 100 cigarettes in lifetime (i.e., eversmoker), and moderate physical activity over the past 30 days (i.e., no or yes) were assessed as descriptives for our sample due to their associations with telomere length $(14,19)$. Hispanic/Latino composition (i.e., Mexican American or other Hispanic) and citizen of the US (i.e., no or yes) were also assessed.

\section{Latent Class Analysis}

The latent or unobserved variable of acculturation was based on six observed acculturation variables and the distal continuous outcome of telomere length (see Figure 1). We conducted our LCA with Mplus 8.6 (Muthén \& Muthén) using a robust maximum likelihood estimator and automatic $\mathrm{BCH}$ approach. The automatic $\mathrm{BCH}$ method-a modification of the approach developed by Bolck, Croon, and Hagenaars (37) - was used to estimate mean telomere length within each profile and compare differences between profiles.

We used a model comparison approach to determine the number of classes. A one-class model up to a seven-class model was subsequently calculated. The one-class model was calculated to assess fit indices and compare with subsequent models. To assess model fit and reliability, we used Bayesian information criterion (BIC), sample-size-adjusted-BIC (ssaBIC), and entropy (i.e., acceptable quality of classification). We evaluated all models based on fit indices and their practical and theoretical considerations.

\section{RESULTS}

The weighted sample was on average $\sim 40$ years of age and equal across gender/sex, with male participants accounting for 49.9 and females $50.1 \%$. The Hispanic/Latino sample was also almost equally weighted between Mexican Americans (50.7\%) and other Hispanics (49.3\%). Most of the sample were citizens of the US (61.6\%) and had more than a High School degree or GED (54.9\%), with a mean family poverty income ratio of 2.04. Much of the weighted sample had not smoked more than 100 cigarettes in their lifetime (56.7\%), nor engaged in at least moderate physical activity over the past 30 days (64.4\%). The Hispanic/Latino mean telomere length was 1.08 T/S ratio. For more details about participant characteristics (see Table 1).

Table 2 has the Hispanic/Latino weighted sample acculturation profile. Most participants lived in the US for 10 years or more $(60.7 \%)$. The largest proportions of the sample used Spanish only as a child (60.2\%), to read and speak (29.7\%), at home (42.9\%), to think (42.0\%), and with friends (35.7\%).

\section{Latent Class Analysis of Acculturation}

The five-class model with low BIC, ssaBIC, and high entropy of 0.891 , as well as the most practical and theoretical considerations, was favored (see Table 3).

Class 1, or the low acculturated profile (33.2\% of sample), with mean telomere length of 1.043 , was composed of Hispanics/Latinos that had the highest conditional probabilities of being in the US $<10$ years. Class 1 had the highest conditional probabilities of using Spanish only during childhood (100\%), to read and speak (88.0\%), at home (99.6\%), to think (99.8\%), and with friends (96.4\%).

Class 2, or the partially integrated profile $(18.6 \%$ of sample), with mean telomere length of 1.102 had a high conditional probability of being in the US more than 10 years (65.5\%). Class 2 had the highest conditional probabilities of using more Spanish than English (but not using Spanish exclusively) to read and speak (75.8\%), at 
TABLE 1 | Descriptive statistics of weighted participant sample $(N=2,292)$.

Frequency (weighted \%) Weighted frequency (SE)

\begin{tabular}{|c|c|c|c|}
\hline \multicolumn{4}{|l|}{ Sex/gender } \\
\hline Male & $1,092(49.9)$ & \multicolumn{2}{|c|}{$11,518,928(1,110,137)$} \\
\hline Female & $1,200(50.1)$ & \multicolumn{2}{|c|}{$11,585,213(1,273,746)$} \\
\hline \multicolumn{4}{|l|}{ Hispanics/Latinos } \\
\hline Mexican Americans & $1,875(50.7)$ & \multicolumn{2}{|c|}{$11,704,451(1,276,076)$} \\
\hline Other Hispanics & $417(49.3)$ & \multicolumn{2}{|c|}{$11,399,691(2,134,279)$} \\
\hline \multicolumn{4}{|c|}{ Citizen of the US $(n=2,277)$} \\
\hline No & $906(38.4)$ & \multicolumn{2}{|c|}{$8,816,781(1,275,864)$} \\
\hline Yes & $1,371(61.6)$ & \multicolumn{2}{|c|}{$14,164,806(1,379,033)$} \\
\hline \multicolumn{4}{|c|}{ Less than high school education $(n=2,287)$} \\
\hline No & $933(54.9)$ & \multicolumn{2}{|c|}{$12,651,015(1,296,845)$} \\
\hline Yes & $1,354(45.1)$ & \multicolumn{2}{|c|}{$10,373,192(1,133,168)$} \\
\hline \multicolumn{4}{|c|}{ Ever-smoker $(n=2,284)$} \\
\hline No & $1,302(56.7)$ & \multicolumn{2}{|c|}{$13,058,383(1,411,389)$} \\
\hline Yes & $982(43.3)$ & \multicolumn{2}{|c|}{$9,986,520(1,055,595)$} \\
\hline \multicolumn{4}{|c|}{ Moderate physical activity over past 30 days $(n=2,289)$} \\
\hline No & $1,152(64.4)$ & \multicolumn{2}{|c|}{$14,876,583(1,646,121)$} \\
\hline \multirow[t]{3}{*}{ Yes } & 737 (35.6) & \multicolumn{2}{|c|}{$8,207,544(821,444)$} \\
\hline & & \multicolumn{2}{|c|}{$95 \%$ CL for Mean } \\
\hline & Mean (SE) & Lower & Upper \\
\hline Age & $40.0(0.592)$ & 38.8 & 41.2 \\
\hline Family PIR $(n=2,060)$ & $2.04(0.061)$ & 1.92 & 2.17 \\
\hline Telomere length & $1.08(0.023)$ & 1.03 & 1.13 \\
\hline
\end{tabular}

PIR, poverty income ratio; SE, Standard Error.

home $(38.3 \%)$, to think (34.5\%), and with friends $(41.5 \%)$. The vast majority (86.1\%) of this class used Spanish only as a child.

Class 3, or the integrated profile (19.4\% of sample), with mean telomere length of 1.084 had a high conditional probability of being in the US more than 10 years $(86.1 \%)$. Class 3 had the highest probabilities of using Spanish and English equally to speak as a child $(28.3 \%)$, to read and speak $(74.6 \%)$, at home (58.7\%), to think (64.4\%), and with friends (74.0\%).

Class 4 , or the partially assimilated (15.2\% of sample), with mean telomere length of 1.108 had the highest conditional probability of being in the US more than 10 years (93.2\%). Class 4 had the highest conditional probabilities of using more English than Spanish to speak as a child (35.5\%), to read and speak $(81.1 \%)$, at home $(49.4 \%)$, to think $(37.5 \%)$, and with friends $(47.8 \%)$.

Class 5, or the assimilated (13.7\% of sample), with mean telomere length of 1.101 had the second-highest conditional probability of being in the US more than 10 years (83.6\%). Class 5 had the highest conditional probabilities of using only English to speak as a child (68.9\%), to read and speak $(68.9 \%)$, at home (100\%), to think (99.9\%), and with friends (97.4\%). See Table 4 for full detail of the latent class conditional probabilities.
TABLE 2 | Acculturation measure responses of weighted participant sample $(N=$ 2,292).

\begin{tabular}{|c|c|c|}
\hline & $\begin{array}{c}\text { Frequency } \\
\text { (weighted \%) }\end{array}$ & Weighted frequency (SE) \\
\hline \multicolumn{3}{|l|}{ Length of time in the US } \\
\hline Less than $1 \mathrm{yr}$ in US & $72(8.1)$ & $1,123,041(284,563)$ \\
\hline More than $1 \mathrm{yr}$, less than $5 \mathrm{yrs}$ & $198(16.4)$ & $2,275,944(421,384)$ \\
\hline More than 5 yrs, less than 10 yrs & $194(14.8)$ & $2,055,003(266,954)$ \\
\hline More than 10 yrs & $882(60.7)$ & $8,409,529(1,432,145)$ \\
\hline \multicolumn{3}{|l|}{ Language used as child } \\
\hline Spanish only & $1,477(60.2)$ & $13,649,132(1,747,330)$ \\
\hline More Spanish than English & $236(10.4)$ & $2,364,162(277,464)$ \\
\hline Both equally & $207(10.7)$ & $2,412,563(293,549)$ \\
\hline More English than Spanish & $178(8.1)$ & $1,834,010(251,671)$ \\
\hline English only & $175(10.6)$ & 2,403,690 (263,529) \\
\hline \multicolumn{3}{|c|}{ Language used to read and speak } \\
\hline Spanish only & $797(29.7)$ & $6,732,782(1,005,467)$ \\
\hline More Spanish than English & $456(20.0)$ & $4,529,867(666,345)$ \\
\hline Both equally & $413(20.2)$ & $4,580,644(449,177)$ \\
\hline More English than Spanish & 413 (19.9) & $4,508,553(526,949)$ \\
\hline English only & $196(10.2)$ & $2,317,946(296,526)$ \\
\hline \multicolumn{3}{|l|}{ Language used at home } \\
\hline Spanish only & 1,082 (42.9) & $9,700,915(1,588,146)$ \\
\hline More Spanish than English & $227(9.7)$ & 2,196,353 $(305,020)$ \\
\hline Both equally & $304(15.1)$ & $3,419,966(407,984)$ \\
\hline More English than Spanish & $271(12.1)$ & $2,736,351(335,478)$ \\
\hline English only & $390(20.2)$ & $4,582,019(406,487)$ \\
\hline \multicolumn{3}{|l|}{ Language used to think } \\
\hline Spanish only & $1,046(42.0)$ & $9,446,896(1,455,867)$ \\
\hline More Spanish than English & $215(8.8)$ & 1,985,948 (23,815) \\
\hline Both equally & $328(15.8)$ & $3,561,690(319,875)$ \\
\hline More English than Spanish & $210(9.2)$ & 2,057,699 $(287,652)$ \\
\hline English only & $466(24.2)$ & $5,449,538(496,264)$ \\
\hline \multicolumn{3}{|l|}{ Language used with friends } \\
\hline Spanish only & $965(35.7)$ & $8,076,402(1,230,584)$ \\
\hline More Spanish than English & $244(9.7)$ & 2,203,670 (401,562) \\
\hline Both equally & $411(21.0)$ & $4,762,837(490,468)$ \\
\hline More English than Spanish & $248(12.7)$ & $2,867,081(343,425)$ \\
\hline English only & 406 (20.9) & 4,726,388 (414,047) \\
\hline
\end{tabular}

SE, Standard Error.

\section{Mean Telomere Length Across Latent Classes}

Telomere length by profiles were compared. The automatic $\mathrm{BCH}$ approach revealed that the equality test of means across classes for the overall differences was not significant $\left(x^{2}=4.54, d f=4\right.$, $p=0.34$ ). See Appendix for Supplementary Table 1 for between class mean comparisons.

\section{DISCUSSION}

Our study using a nationally representative sample identified five profiles of Hispanic/Latino linguistic acculturation and their respective telomere length. In using the five SASH items in conjunction with time spent in the US we were able to 
TABLE 3 | Latent class analysis fit criteria of acculturation and telomere length models.

\begin{tabular}{lccc}
\hline Model & BIC & ssaBIC & Entropy \\
\hline One-class solution & 35576.764 & 35503.688 & - \\
Two-class solution & 28410.596 & 28261.268 & 0.944 \\
Three-class solution & 26075.609 & 25850.030 & 0.929 \\
Four-class solution & 25309.857 & 25008.025 & 0.906 \\
Five-class solution & 24869.397 & 24491.313 & 0.891 \\
Six-class solution & 24801.132 & 24346.796 & 0.898 \\
Seven-class solution & 24823.808 & 24293.220 & 0.897 \\
\hline
\end{tabular}

BIC, Bayesian information criteria; ssaBIC, sample size adjusted BIC.

create more dynamic profiles based on the acculturative process. The acculturative process involves language and behavioral norm acquisition from prolonged contact with the host culture (2, 30). US Hispanics/Latinos have been reported to have various acculturation strategies that include marginalization (i.e., rejection of both native and host culture), segregation (i.e., non-integration into the host culture), enculturation, integration, or assimilation (24, 38-40). Enculturation is often operationalized as reintegration or relearning of an individual's native culture (24). Integration is the process where an individual adopts aspects of the host culture without the loss of their native culture (1). Assimilation is the process where the individual replaces aspects of the native culture with those adopted from the host culture (1). The process of assimilation in the acculturative process can be a source of high psychosocial stress due to feelings of otherness and discrimination $(34,40,41)$, as well as the lifestyles changes that lead to a loss of social support and unhealthy behaviors $(23,42,43)$. The psychosocial effects are prominent in subsequent generations, as protective health behaviors and support structures from the native culture diminish. Moreover, Hispanic/Latino groups are reported to experience worse health outcomes as they become more similar to their US counterparts (24).

Language serves as a primary factor to integration into a new host culture (28). For instance, in reviewing the low acculturated (Class 1) profile of US Hispanics/Latinos that almost exclusively used Spanish regardless of time spent living in the US, two patterns emerged in this profile that will require further examination. First, the low acculturated profile had an approximate conditional probability of $34 \%$ to be in the US $<1$ year and between 1 and $<5$ years, which would explain the Spanish only linguistic acculturation. Newly arrived immigrant groups will learn the host country's culture and language, or that is the expectation of the host country for the newly immigrated (1, 2, 44). Second, the highest conditional probability of time spent in the US, was $47 \%$ on 10 years or more. The high conditional probability of being in the US for a decade or longer in juxtaposition of Spanish only linguistic acculturation may be indicative of low acculturation due to marginalized or segregated individuals as described by Berry $(1,44)$. The low acculturated profile represented the largest subgroup across all identified profiles.

While it is difficult to ascertain whether persons are marginalized and segregated in our study, it should be noted that low acculturated individuals have been reported to experience worse mental health outcomes (38). The effect of low acculturation and telomere length is less clear. Some studies have found linear associations with lower acculturated groups and decreased telomere length when compared to more acculturated or assimilated groups $(45,46)$. Specifically, a study by Ruiz and colleagues (14) reported that among pregnant Mexican mothers there is a complex association between low acculturation and decreased telomere length in the presence of psychosocial stress. Inversely, a study among Mexican women in the US reported that among the high acculturation group, longer telomeres were associated with increased percentage body fat but reported no association with low acculturated women (47). In our study, while we found that the low acculturated group had the lowest mean telomere length, it was not significantly different from all other acculturation profiles. Future studies must consider other factors from joint pathologies or other disease etiologies, in addition to environments that may facilitate acculturation strategies such as marginalization or segregation.

Nevertheless, environmental data from built-environmental features, community compositions, and neighborhoods were not available for use in our model, but we must acknowledge their role in linguistic acculturation. Discrimination and discriminatory policies that may be linguistically biased must also be considered to understand low acculturation in context of segregation and marginalization in an environmental context $(1,2,30)$. The neighborhood environment, however, may have protective or detrimental effects to the newly introduced immigrant's health based on individual and family language usage (48-50). Neighborhood racial and ethnic composition may also have a role in linguistic acculturation, and their selected acculturation strategy $(51,52)$.

By contrast, the partially integrated (Class 2) spoke more Spanish than English and were more likely than the low acculturated class to have lived in the US 10 or more years $(65.5 \%$ conditional probability). The integrated (Class 3 ) was comprised of Hispanics/Latinos living in the US 10 or more years that used English and Spanish equally, at home, to think, to read and speak, and with friends. The integrated profiles may indicate biculturalism or adaptive profiles. While the integrated profiles are often adaptive, there are some mental and physiological health concerns. Hispanics/Latinos in this adaptive bicultural process adopt customs and language norms that will benefit their integration into the larger US culture $(24,38,40)$. Issues concerning identity are at the crux of this process as the degree to which Hispanics/Latinos have a choice to enculturate, integrate, or assimilate is unknown as are the health consequences.

Most individuals (57.8\%) in the integrated class used at least some English during childhood-although a plurality (42.2\%) of them solely spoke Spanish during this period of their lives. More than two-fifths (42.2\%) of people in this class used Spanish 
TABLE 4 | Conditional probabilities of 5-class solution from latent class model $(N=2,282)$.

\begin{tabular}{|c|c|c|c|c|c|}
\hline & $\begin{array}{c}\text { Class 1: } \\
\text { Low acculturated } \\
33.2 \%(n=757)\end{array}$ & $\begin{array}{c}\text { Class 2: } \\
\text { Partially integrated } \\
18.6 \%(n=424)\end{array}$ & $\begin{array}{c}\text { Class 3: } \\
\text { Integrated } \\
19.4 \%(n=442)\end{array}$ & $\begin{array}{c}\text { Class 4: } \\
\text { Partially assimilated } \\
15.1 \%(n=346)\end{array}$ & $\begin{array}{c}\text { Class } 5 \\
\text { Assimilated } \\
13.7 \%(n=312)\end{array}$ \\
\hline \multicolumn{6}{|l|}{ Length of time in the US } \\
\hline Less than $1 \mathrm{yr}$ in US & 0.113 & 0.081 & 0.000 & 0.000 & 0.000 \\
\hline More than $1 \mathrm{yr}$, less than $5 \mathrm{yrs}$ & 0.231 & 0.112 & 0.051 & 0.068 & 0.164 \\
\hline More than $5 \mathrm{yrs}$, less than $10 \mathrm{yrs}$ & 0.182 & 0.152 & 0.088 & 0.000 & 0.000 \\
\hline 10 yrs or more years & 0.473 & 0.655 & 0.861 & 0.932 & 0.836 \\
\hline \multicolumn{6}{|l|}{ Language used as child } \\
\hline Spanish only & 1.000 & 0.861 & 0.422 & 0.161 & 0.017 \\
\hline More Spanish than English & 0.000 & 0.115 & 0.231 & 0.196 & 0.053 \\
\hline Both equally & 0.000 & 0.023 & 0.283 & 0.221 & 0.103 \\
\hline More English than Spanish & 0.000 & 0.000 & 0.024 & 0.355 & 0.138 \\
\hline English only & 0.000 & 0.000 & 0.040 & 0.067 & 0.689 \\
\hline \multicolumn{6}{|l|}{ Language used to read and speak } \\
\hline Spanish only & 0.880 & 0.038 & 0.006 & 0.000 & 0.000 \\
\hline More Spanish than English & 0.120 & 0.758 & 0.053 & 0.019 & 0.000 \\
\hline Both equally & 0.000 & 0.195 & 0.746 & 0.133 & 0.037 \\
\hline More English than Spanish & 0.000 & 0.010 & 0.149 & 0.811 & 0.275 \\
\hline English only & 0.000 & 0.000 & 0.046 & 0.037 & 0.689 \\
\hline \multicolumn{6}{|l|}{ Language used at home } \\
\hline Spanish only & 0.996 & 0.416 & 0.065 & 0.050 & 0.000 \\
\hline More Spanish than English & 0.003 & 0.383 & 0.096 & 0.023 & 0.000 \\
\hline Both equally & 0.001 & 0.082 & 0.587 & 0.160 & 0.000 \\
\hline More English than Spanish & 0.000 & 0.028 & 0.184 & 0.494 & 0.000 \\
\hline English only & 0.000 & 0.091 & 0.068 & 0.273 & 1.000 \\
\hline \multicolumn{6}{|l|}{ Language used to think } \\
\hline Spanish only & 0.988 & 0.425 & 0.054 & 0.006 & 0.000 \\
\hline More Spanish than English & 0.007 & 0.345 & 0.074 & 0.032 & 0.000 \\
\hline Both equally & 0.005 & 0.185 & 0.644 & 0.028 & 0.000 \\
\hline More English than Spanish & 0.000 & 0.041 & 0.116 & 0.375 & 0.001 \\
\hline English only & 0.000 & 0.004 & 0.112 & 0.559 & 0.999 \\
\hline \multicolumn{6}{|l|}{ Language used with friends } \\
\hline Spanish only & 0.964 & 0.189 & 0.018 & 0.000 & 0.000 \\
\hline More Spanish than English & 0.022 & 0.415 & 0.029 & 0.021 & 0.003 \\
\hline Both equally & 0.011 & 0.260 & 0.740 & 0.122 & 0.003 \\
\hline More English than Spanish & 0.003 & 0.088 & 0.145 & 0.478 & 0.020 \\
\hline English only & 0.000 & 0.047 & 0.068 & 0.380 & 0.974 \\
\hline \multicolumn{6}{|l|}{ Telomere length } \\
\hline Mean T/S ratio (SE) & $1.043(.033)$ & $1.102(.037)$ & $1.084(.034)$ & $1.108(.033)$ & $1.101(.031)$ \\
\hline
\end{tabular}

SE, Standard Error.

only as a child. The integrated class indicated possible language use change over time. Interestingly, even though the conditional probability of using more English than Spanish to think was highest for this class, a majority of people (55.9\%) in the partially assimilated (Class 4) reported using English only to think. The partially assimilated (Class 4 ) were those with the highest likelihood of living in the US 10 or more years and using more English than Spanish but not exclusively English to read and speak, at home, and with friends. The partially assimilated class illustrated the importance of social context for language use, as many individuals continued to use Spanish frequently in their lives despite reporting English use for thinking. The assimilated (Class 5) were those living in the US 10 or more years and had the highest conditional probability to speak only English as a child. The majority of the assimilated exclusively spoke English only as a child, to read and speak, at home, to think, and with friends.

Assimilation in first generation individuals can be stressful, compared to subsequent generations $(24,53)$. The process of 
assimilation in subsequent generations is often classified as either congruent or dissonant between parents and children (54). The assimilated classes from our findings could be indicative of second or subsequent generations of Hispanics/Latinos in our sample. Findings suggest a generational effect in the partial assimilation (Class 4) and assimilation (Class 5) as the profiles have an overall lower probability of using Spanish and a higher probability of speaking more English as children, respectively, to other profiles. The partially assimilated primarily had a higher probability of speaking more English than Spanish as children (i.e., 35.5\% conditional probability). To contrast, the assimilated profile had the highest probability to speak English only as children $(68.9 \%$ conditional probability).

Overall, using our LCA on a US representative sample of Hispanic/Latinos we identified heterogenous classes of acculturation that may reveal differences in experiences and processes, which were theoretically suggested in the literature. Linguistic acculturation can be a powerful indicator of risk, but more may be needed to detect telomere length differences between subgroups. While various reasons can be attributed as to why significant telomere differences were not detected, linguistic acculturation may be indicative of other psychosocial stressors and adaptive strategies. For instance, while language can be a source of insecurities and discrimination it can also be key to facilitate equitable access to healthcare and mental health services. In context of our findings, the largest subgroup was low acculturated with almost exclusive Spanish use while having lived in the US for 5 or more years. This may be indicative that a large proportion of US Hispanics/Latinos speak only Spanish, which may affect their access and quality of health services. Nonetheless, linguistic interventions will not be enough to mitigate the possible disparity. Spanish interpreters or translated health materials are a start but literacy and cultural empathy are critical to intervene or prevent excess risk by incorporating customs, norms, and behaviors that are conducive to health among US Hispanics/Latinos. To mitigate disparities and promote health equity, future studies must collect environmental and community data, as well as biomarkers of risk to create more comprehensive models. These comprehensive models may be used to confirm if profiles from our findings remain consistent or detect telomeric differences. Telomere differences may be indicative of increased morbidity and mortality among certain subpopulations (55). As such, the importance of detecting telomere length by acculturation may, for instance, be the critical difference in identifying cancer risk or preventing cancer among Mexican Americans (56). Lastly, in using more comprehensive person-level approaches we can model risk contextually to not only understand syndemic vulnerabilities - the synergy of disease outcomes interacting with comorbid conditions, as well as other social, cultural, biological, and environmental determinants in context of human rights (57) - but to also help develop tailored interventions and prevention programs for those at increased risk from among the most at-risk $(24,47,53,54)$.

\section{LIMITATIONS AND STRENGTHS}

Our study had four major limitations. The first was that the data, although nationally representative, were cross-sectional; therefore, we were unable to examine changes within the sample over time. Still, various published studies and reports have demonstrated that the data are of acceptable quality $(11-13,58)$. Second, acculturation is a complex, dynamic multidimensional process. Acculturation measures that exclusively use linguistic measures to assess the process have been critiqued $(30,53)$. Nonetheless, the validated SASH measure serves as a measure to assess a facet of acculturative strategies (29). Third, the telomere data were not from the current NHANES as they are only accessible from the 1999-2002 cycles. The fourth limitation concerns the meaningfulness of telomere length data in health outcomes research. While telomere research continues to be refined, the interpretation of telomere length and outcomes on morbidity and mortality are less direct $(11-13,59)$ and may explain why no significant telomere length differences were detected. Although more advanced methods from a manual $\mathrm{BCH}$ auxiliary regression approach in Mplus (37) would allow us to test the effects of covariates on classes, we would not be able to test differences of telomere length by class. Additionally, the manual approach would not permit us to test telomere length differences between profiles.

Our study also possessed notable strengths, as it is among the first to focus on acculturation and telomere length, a complex biomarker of senescence and risk. We used the most current techniques for available software packages to assess acculturation profiles and biological processes using complex survey design data of US Hispanics/Latinos. Future research will incorporate multiple acculturation factors beyond language measures to assess its impact on health biomarkers in the context of syndemic vulnerability and risk. A syndemic and latent variable approach will be critical as various factors co-occur and synergize to affect biological processes occurring in tandem without a priori categorization to capture person-centered contexts.

\section{CONCLUSION}

We identified five Hispanic/Latino acculturation profiles at possible differential risk of shorter telomere length, but no significant telomere length differences emerged. Specifically, our findings will contribute to the emerging literature on the relationship between acculturation profiles and associated biomarkers of health and disease. Our findings and approach provide a way to identify groups most at-risk in already vulnerable subpopulations. Through this work we can understand contextual risk, as well as develop prevention programs and targeted health interventions among US Hispanic/Latino groups. The implications of this research will be to examine the dynamic effects of acculturation using comprehensive models of risk biomarkers to develop prevention programs in order to mitigate health disparities and move toward health equity. 


\section{DATA AVAILABILITY STATEMENT}

$\begin{array}{lll}\text { Publicly available datasets were } & \text { analyzed } \\ \text { in this study. This data can be found }\end{array}$ at: https://wwwn.cdc.gov/nchs/nhanes/Default.aspx.

\section{AUTHOR CONTRIBUTIONS}

FM: conceptualization, data curation, methodology, formal analysis, visualization, roles, writing-original draft, and writing-review and editing. PM: roles, writing-original draft, conceptualization, and writing-review and editing. $\mathrm{KV}$ : conceptualization and writing-review and editing. JC: resources, roles, writing-original draft, supervision, and validation. AN: roles, writing-original draft, writingreview and editing, supervision, and validation. FW: project administration, resources, software, supervision, writingreview and editing, and validation. All authors contributed to the article and approved the submitted version.

\section{REFERENCES}

1. Berry JW. Conceptual approaches to acculturation. In: Chun KM, Balls Organista P, Marin G, editors. Acculturation: Advances in Theory, Measurement, and Applied Research. XXVII. Washington, DC: American Psychological Association (2003). p. 17-37.

2. Berry JW. Acculturation: Living successfully in two cultures. Int J Intercult Relat. (2005) 29:697-712. doi: 10.1016/j.ijintrel.2005.07.013

3. Fox M, Thayer Z, Wadhwa PD. Assessment of acculturation in minority health research. Soc Sci Med. (2017) 176:12332. doi: 10.1016/j.socscimed.2017.01.029

4. Fox M, Thayer ZM, Wadhwa PD. Acculturation and health: the moderating role of sociocultural context. Am Anthropol. (2017) 119:405-21. doi: 10.1111/aman.12867

5. Biegler KA, Anderson AK, Wenzel LB, Osann K, Nelson EL. Longitudinal change in telomere length and the chronic stress response in a randomized pilot biobehavioral clinical study: implications for cancer prevention. Cancer Prev Res. (2012) 5:1173-82. doi: 10.1158/1940-6207.CAPR-12-0008

6. Starr JM, Shiels PG, Harris SE, Pattie A, Pearce MS, Relton CL, et al. Oxidative stress, telomere length and biomarkers of physical aging in a cohort aged 79 years from the 1932 Scottish Mental Survey. Mech Ageing Dev. (2008) 129:745-51. doi: 10.1016/j.mad.2008.09.020

7. Lin J, Epel E, Blackburn E. Telomeres and lifestyle factors: roles in cellular aging. Mutat Res. (2012) 730:85-9. doi: 10.1016/j.mrfmmm.2011.08.003

8. Deng Y, Chan SS, Chang S. Telomere dysfunction and tumour suppression: the senescence connection. Nat Rev Cancer. (2008) 8:450-8. doi: $10.1038 / \mathrm{nrc} 2393$

9. Loprinzi PD. Cardiorespiratory capacity and leukocyte telomere length among adults in the United States. Am J Epidemiol. (2015) 182:198201. doi: 10.1093/aje/kwv056

10. Serrano AL, Andrés V. Telomeres and cardiovascular disease: does size matter? Circ Res. (2004) 94:57584. doi: 10.1161/01.RES.0000122141.18795.9C

11. Needham BL, Adler N, Gregorich S, Rehkopf D, Lin J, Blackburn EH, et al. Socioeconomic status, health behavior, and leukocyte telomere length in the National Health and Nutrition Examination Survey, 1999-2002. Soc Sci Med. (2013) 85:1-8. doi: 10.1016/j.socscimed.2013.02.023

12. Needham BL, Mezuk B, Bareis N, Lin J, Blackburn EH, Epel ES. Depression, anxiety and telomere length in young adults: evidence from the National Health and Nutrition Examination Survey. Mol Psychiatry. (2015) 20:5208. doi: $10.1038 / \mathrm{mp} .2014 .89$

13. Needham BL, Rehkopf D, Adler N, Gregorich S, Lin J, Blackburn $\mathrm{EH}$, et al. Leukocyte telomere length and mortality in the National

\section{FUNDING}

The efforts of KV, FM, AN, and FW were supported by the Division of Intramural Research - National Institute on Minority Health and Health Disparities, National Institutes of Health.

\section{ACKNOWLEDGMENTS}

We would like to thank Claire Rowan for their valuable input and support in this work.

\section{SUPPLEMENTARY MATERIAL}

The Supplementary Material for this article can be found online at: https://www.frontiersin.org/articles/10.3389/fpubh. 2021.640226/full\#supplementary-material

Health and Nutrition Examination Survey, 1999-2002. Epidemiology. (2015) 26:528. doi: 10.1097/EDE.0000000000000299

14. Ruiz RJ, Trzeciakowski J, Moore T, Ayers KS, Pickler RH. Acculturation predicts negative affect and shortened telomere length. Biol Res Nurs. (2017) 19:28-35. doi: 10.1177/1099800416672005

15. Maser RS, DePinho RA. Connecting chromosomes, crisis, and cancer. Science. (2002) 297:565-9. doi: 10.1126/science.297.5581.565

16. Martínez-Cué C, Rueda N. Cellular senescence in neurodegenerative diseases. Front Cell Neurosci. (2020) 14:16. doi: 10.3389/fncel.2020.00016

17. Wojcicki JM, Elwan D, Lin J, Blackburn E, Epel E. Chronic obesity and incident hypertension in Latina women are associated with accelerated telomere length loss over a 1-year period. Metab Syndr Relat Disord. (2018) 16:262-6. doi: 10.1089/met.2017.0134

18. Leung CW, Laraia BA, Needham BL, Rehkopf DH, Adler NE, Lin J, et al. Soda and cell aging: associations between sugar-sweetened beverage consumption and leukocyte telomere length in healthy adults from the National Health and Nutrition Examination Surveys. Am J Public Health. (2014) 104:242531. doi: 10.2105/AJPH.2014.302151

19. Geronimus AT, Pearson JA, Linnenbringer E, Schulz AJ, Reyes AG, Epel ES, et al. Race-ethnicity, poverty, urban stressors, and telomere length in a Detroit community-based sample. J Health Soc Behav. (2015) 56:199224. doi: 10.1177/0022146515582100

20. Patel CJ, Manrai AK, Corona E, Kohane IS. Systematic correlation of environmental exposure and physiological and self-reported behaviour factors with leukocyte telomere length. Int J Epidemiol. (2017) 46:4456. doi: 10.1093/ije/dyw043

21. Daviglus ML, Talavera GA, Avilés-Santa ML, Allison M, Cai J, Criqui MH, et al. Prevalence of major cardiovascular risk factors and cardiovascular diseases among Hispanic/Latino individuals of diverse backgrounds in the United States. JAMA. (2012) 308:1775-84. doi: 10.1001/jama.2012.14517

22. Lee RD, Chen J. Adverse childhood experiences, mental health, and excessive alcohol use: examination of race/ethnicity and sex differences. Child Abuse Negl. (2017) 69:40-8. doi: 10.1016/j.chiabu.2017.04.004

23. Abraído-Lanza AF, Chao MT, Florez KR. Do healthy behaviors decline with greater acculturation? Implications for the Latino mortality paradox. Soc Sci Med. (2005) 61:1243-55. doi: 10.1016/j.socscimed.2005.01.016

24. Alamilla SG, Kim BSK, Lam NA. Acculturation, enculturation, perceived racism, minority status stressors, and psychological symptomatology among Latino/as. Hisp J Behav Sci. (2010) 32:55-76. doi: 10.1177/0739986309352770

25. Rej PH, HEAT Steering Committee, Gravlee CC, Mulligan CJ. Shortened telomere length is associated with unfair treatment attributed to race in African Americans living in Tallahassee, Florida. Am J Hum Biol. (2019) 32:e23375. doi: 10.1002/ajhb.23375 
26. Chae DH, Epel ES, Nuru-Jeter AM, Lincoln KD, Taylor RJ, Lin J, et al. Discrimination, mental health, and leukocyte telomere length among African American men. Psychoneuroendocrinology. (2016) 63:106. doi: 10.1016/j.psyneuen.2015.09.001

27. Chae DH, Wang Y, Martz CD, Slopen N, Yip T, Adler NE, et al. Racial discrimination and telomere shortening among African Americans: the Coronary Artery Risk Development in Young Adults (CARDIA) study. Health Psychol. (2020) 39:209-19. doi: 10.1037/hea0000832

28. Marin G, Sabogal F, Marin BV, Otero-Sabogal R, Perez-Stable EJ. Development of a short acculturation scale for hispanics. Hisp J Behav Sci. (1987) 9:183205. doi: 10.1177/07399863870092005

29. Hamilton AS, Hofer TP, Hawley ST, Morrell D, Leventhal M, Deapen D, et al. Latinas and breast cancer outcomes: population-based sampling, ethnic identity, and acculturation assessment. Cancer Epidemiol Prev Biomarkers. (2009) 18:2022-9. doi: 10.1158/1055-9965.EPI-09-0238

30. Berry JW. A critique of critical acculturation. Int J Intercult Relat. (2009) 33:361-71. doi: 10.1016/j.ijintrel.2009.06.003

31. Meeusen C, Meuleman B, Abts K, Bergh R. Comparing a variable-centered and a person-centered approach to the structure of prejudice. Soc Psychol Personal Sci. (2017) 9:645-55. doi: 10.1177/1948550617720273

32. Howard MC, Hoffman ME. Variable-centered, person-centered, and personspecific approaches: where theory meets the method. Organ Res Methods. (2017) 21:846-76. doi: 10.1177/1094428117744021

33. Zipf G, Chiappa M, Porter KS, Ostchega Y, Lewis BG, Dostal J. National health and nutrition examination survey: plan and operations, 1999-2010. Vital Health Stat 1. (2013) 1:1-37.

34. Caplan S. Latinos, acculturation, and acculturative stress: a dimensional concept analysis. Policy Polit Nurs Pract. (2007) 8:93-106. doi: 10.1177/1527154407301751

35. Leclere FB, Jensen L, Biddlecom AE. Health care utilization, family context, and adaptation among immigrants to the United States.J Health Soc Behav. (1994) 35:370-84. doi: 10.2307/2137215

36. Lee S, O'Neill AH, Ihara ES, Chae DH. Change in self-reported health status among immigrants in the United States: associations with measures of acculturation. PLoS ONE. (2013) 8:e76494. doi: 10.1371/journal.pone.0076494

37. Asparouhov T, Muthén B. Auxiliary Variables in Mixture Modeling: Using the BCH Method in Mplus to Estimate a Distal Outcome Model and an Arbitrary Second Model. (2014). Available online at: http://www.statmodel. com/examples/webnote.shtml (accessed March 17, 2019).

38. Meca A, Schwartz SJ, Martinez CR, McClure HH. Longitudinal effects of acculturation and enculturation on mental health: does the measure of matter? Dev Psychopathol. (2018) 30:1849-66. doi: 10.1017/S0954579418001165

39. Yoon E, Chang CT, Kim S, Clawson A, Cleary SE, Hansen M, et al. A metaanalysis of acculturation/enculturation and mental health. J Couns Psychol. (2013) 60:15. doi: 10.1037/a0030652

40. Lee DL, Ahn S. Discrimination against Latina/os: a meta-analysis of individual-level resources and outcomes. Couns Psychol. (2012) 40:2865. doi: 10.1177/0011000011403326

41. Torres L. Predicting levels of Latino depression: acculturation, acculturative stress, and coping. Cultur Divers Ethnic Minor Psychol. (2010) 16:25663. doi: 10.1037/a0017357

42. Giuntella O, Stella L. The acceleration of immigrant unhealthy assimilation. Health Econ. (2017) 26:511-8. doi: 10.1002/hec.3331

43. Bulut E, Gayman MD. A latent class analysis of acculturation and depressive symptoms among Latino immigrants: Examining the role of social support. Int J Intercult Relat. (2020) 76:13-25. doi: 10.1016/j.ijintrel.2020. 02.002

44. Berry JW. Cultural Relations in Plural Societies: Alternatives to Segregation and Their Sociopsychological Implications. In: Miller N, Brewer MB, editors. Groups in Contact. Orlando, FL: Academic Press (1984). p. 11-27.

45. Gonzalez-Guarda RM, Stafford AM, Nagy GA, Befus DR, Conklin JL. A systematic review of physical health consequences and acculturation stress among latinx individuals in the United States. Biol Res Nurs. (2020) 23:36274. doi: 10.1177/1099800420968889

46. Coimbra BM, Carvalho CM, Ota VK, Vieira-Fonseca T, Bugiga A, Mello AF, et al. A systematic review on the effects of social discrimination on telomere length. Psychoneuroendocrinology. (2020) 120:104766. doi: 10.1016/j.psyneuen.2020.104766
47. Aguayo L, Ogolsky B, Teran-Garcia M, Pineros-Leano M, Wiley A, Lin J, et al. From culture to chromosomes: a mother-child dyadic study of acculturation, telomere lengths and body fat. Compr Psychoneuroendocrinology. (2021) 5:100029. doi: 10.1016/j.cpnec.2021.100029

48. Hansen MC, Aranda MP. Sociocultural influences on mental health service use by Latino older adults for emotional distress: exploring the mediating and moderating role of informal social support. Soc Sci Med. (2012) 75:213442. doi: 10.1016/j.socscimed.2012.06.029

49. Gonzales NA, Deardorff J, Formoso D, Barr A, Barrera M Jr. Family mediators of the relation between acculturation and adolescent mental health. Fam Relat. (2006) 55:318-30. doi: 10.1111/j.1741-3729.2006.00405.x

50. Gonzales NA, Knight GP, Morgan-Lopez AA, Saenz D, Sirolli A. Acculturation and the mental health of Latino youths: An integration and critique of the literature. In; Contreras JM, Kerns KA, Neal-Barnett AM, editors. Latino Children and Families in the United States: Current Research and Future Directions. (2002). p. 45-74.

51. Capielo Rosario C, Adames HY, Chavez-Dueñas NY, Renteria R. Acculturation profiles of central florida puerto ricans: examining the influence of skin color, perceived ethnic-racial discrimination, and neighborhood ethnic-racial composition. J Cross Cult Psychol. (2019) 50:556-76. doi: 10.1177/0022022119835979

52. Cheung-Blunden VL, Juang LP. Expanding acculturation theory: are acculturation models and the adaptiveness of acculturation strategies generalizable in a colonial context? Int J Behav Dev. (2008) 32:2133. doi: $10.1177 / 0165025407084048$

53. Horevitz E, Organista KC. The Mexican health paradox: expanding the explanatory power of the acculturation construct. Hisp J Behav Sci. (2013) 35:3-34. doi: 10.1177/0739986312460370

54. Portes A, Rivas A. The adaptation of migrant children. Future Child. (2011) 21:219-46. doi: 10.1353/foc.2011.0004

55. Blackburn EH, Epel ES, Lin J. Human telomere biology: a contributory and interactive factor in aging, disease risks, and protection. Science. (2015) 350:1193-8. doi: 10.1126/science.aab3389

56. Han L, Zhao H, Strom S, Daniel CR, Chang D, Zhang H, et al. Abstract 5038: telomere length linking social contexts and cancer risk in Mexican Americans. Cancer Res. (2014) 74:5038. doi: 10.1158/1538-7445.AM2014-5038

57. Willen SS, Knipper M, Abadía-Barrero CE, Davidovitch N. Syndemic vulnerability and the right to health. Lancet. (2017) 389:964-77. doi: 10.1016/S0140-6736(17)30261-1

58. Rehkopf DH, Needham BL, Lin J, Blackburn EH, Zota AR, Wojcicki $\mathrm{JM}$, et al. Leukocyte telomere length in relation to 17 biomarkers of cardiovascular disease risk: a cross-sectional study of US adults. PLoS Med. (2016) 13:e1002188. doi: 10.1371/journal.pmed.1002188

59. Cesare AJ, Reddel RR. Alternative lengthening of telomeres: models, mechanisms and implications. Nat Rev Genet. (2010) 11:319. doi: $10.1038 / \operatorname{nrg} 2763$

Author Disclaimer: The content is solely the responsibility of the authors and does not necessarily reflect the views of the National Institutes of Health.

Conflict of Interest: The authors declare that the research was conducted in the absence of any commercial or financial relationships that could be construed as a potential conflict of interest.

Publisher's Note: All claims expressed in this article are solely those of the authors and do not necessarily represent those of their affiliated organizations, or those of the publisher, the editors and the reviewers. Any product that may be evaluated in this article, or claim that may be made by its manufacturer, is not guaranteed or endorsed by the publisher.

Copyright (C) 2021 Montiel Ishino, McNab, Villalobos, Cohen, Nápoles and Williams. This is an open-access article distributed under the terms of the Creative Commons Attribution License (CC BY). The use, distribution or reproduction in other forums is permitted, provided the original author(s) and the copyright owner(s) are credited and that the original publication in this journal is cited, in accordance with accepted academic practice. No use, distribution or reproduction is permitted which does not comply with these terms. 